\title{
Neuro-Ophthalmological Manifestations in Children with Down Syndrome: Current Perspectives
}

\author{
Lavinia Postolache (D) \\ Anne Monier ${ }^{2}$ \\ Sophie Lhoir' \\ 'Department of Pediatric Ophthalmology, \\ Queen Fabiola University Children's \\ Hospital, Université Libre de Bruxelles, \\ Brussels, Belgium; ${ }^{2}$ Department of \\ Pediatric Neurology, Queen Fabiola \\ University Children's Hospital, Université \\ Libre de Bruxelles, Brussels, Belgium
}

\begin{abstract}
Down syndrome, caused by an extra copy of all or part of chromosome 21, is the most prevalent intellectual disability of genetic origin. Among numerous comorbidities which are part of the phenotype of individuals with Down syndrome, ocular problems appear to be highly prevalent. Neuro-ophthalmological manifestations, such as ocular alignment and motility disturbances, amblyopia, hypoaccommodation or optic nerve abnormalities, and other organic ocular anomalies frequently reported in Down syndrome, may lead to an overall decrease in visual acuity. Although numerous studies have reported ocular anomalies related to Down syndrome, it remains challenging to determine the impact of each anomaly upon the decreased visual acuity, as most such individuals have more than one ocular problem. Even in children with Down syndrome and no apparent ocular defect, visual acuity has been found to be reduced compared with typically developing children. Pediatric ophthalmological examination is a critical component of a multidisciplinary approach to prevent and treat ocular complications and improve the visual outcome in children with Down syndrome. This narrative review aims to provide a better understanding of the neuroophthalmological manifestations and discuss the current ophthalmological management in children with Down syndrome.
\end{abstract}

Keywords: Down syndrome, trisomy 21, ocular anomalies, pediatric ophthalmology, strabismus, optic nerve, hypoaccommodation, nystagmus

\section{Introduction}

Down syndrome, also known as trisomy 21, is the most common autosomal aneuploidy, with an overall incidence of 1 in 1000 live births. ${ }^{1}$ Caused by an extra copy of all or part of chromosome 21, Down syndrome is also the most common form of intellectual disability of recognized genetic origin. ${ }^{2}$ The phenotype of Down syndrome comprises more than 80 clinical features that are variable in presence and severity. ${ }^{3}$ Some features such as facial dysmorphism, cognitive impairment, and neonatal hypotonia occur in all individuals with Down syndrome. ${ }^{4}$

It remains poorly understood why the majority of comorbidities appear in some but not all individuals with Down syndrome, ${ }^{5}$ none of those comorbidities being specific to the syndrome and all of them being also encountered in euploid individuals. ${ }^{6}$

Approximately half of infants with Down syndrome have at least one major congenital anomaly ${ }^{7-10}$ versus only $0.82 \%$ in the general population. ${ }^{11}$ The most common major anomalies are congenital heart defects followed by digestive and genitourinary malformations. ${ }^{10,12}$ Various other comorbidities, such as Alzheimer's type dementia, ${ }^{13}$ immune and autoimmune disturbances ${ }^{14-16}$ or endocrine disorders, ${ }^{17,18}$ appear later in life.
Correspondence: Lavinia Postolache Department of Pediatric Ophthalmology, Queen Fabiola University Children's Hospital, Université Libre de Bruxelles, Belgium (Hôpital Universitaire des Enfants Reine Fabiola) 15, av JJ Crocq, Brussels, 1020, Belgique

Tel +324772189

Email Lavinia.Postolache@huderf.be 
Ocular anomalies, though not the most severely handicapping, are frequently encountered, with most children with Down syndrome having at least one such condition. ${ }^{19-24}$

Some of these anomalies, such as slanting palpebral fissures, epicanthal folds, ${ }^{22}$ Brushfield spots (Figure 1C), and peripheral iris thinning, may have no impact on vision. ${ }^{19,20,25}$

Most children with Down syndrome have decreased visual acuity, ${ }^{26,27}$ which may be due to factors such as significant refractive errors, strabismus, amblyopia, ${ }^{23}$ nystagmus, ${ }^{27,28}$ hypoaccommodative ability, ${ }^{26,29}$ and cataracts. ${ }^{30} \mathrm{~A}$ failure of development of the higher visual pathways, as suggested by Woodhouse and colleagues, ${ }^{26}$ could further decrease their visual acuity, even in those children with Down syndrome and no major ocular defects. Visual deficiency in children with Down syndrome, especially the inability to clearly see near targets, may lead to poor intellectual achievements. ${ }^{29}$

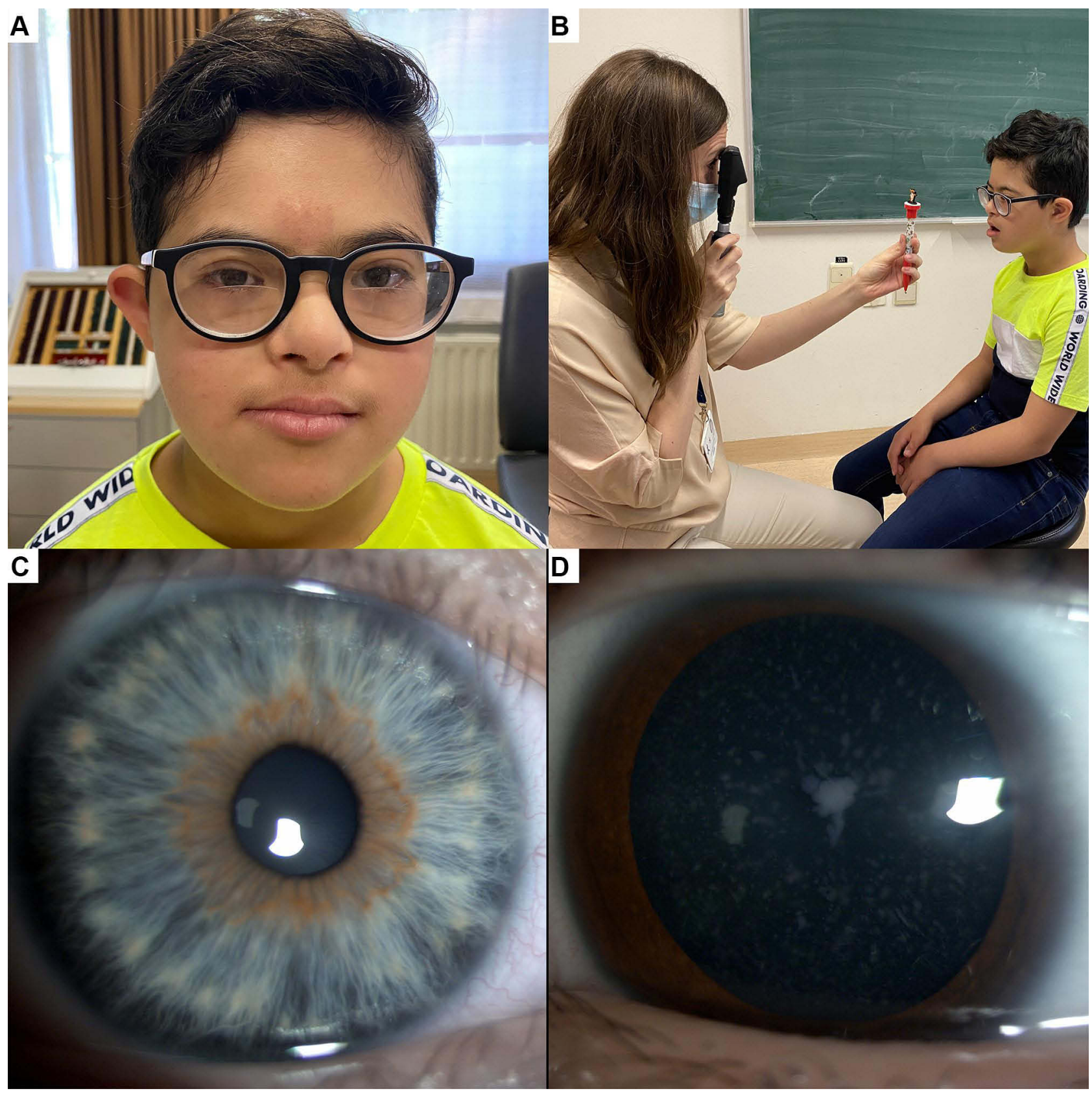

Figure I Ocular anomalies in Down syndrome. (A) Eleven year old boy with Down syndrome, myopia and hypoaccommodation wearing bifocal spectacles. (B) Evaluation of accommodation by dynamic retinoscopy. (C) Brushfield spots: white iris nodules arranged circumferentially; an area of thinner iris stroma is noted peripheral to the nodules. (D) Blue dots cataract in a 16 year old boy with Down syndrome. 
The ophthalmologist has a critical role in the diagnosis and treatment of ocular and neuro-ophthalmological comorbidities in Down syndrome and a comprehensive understanding of related manifestations in children with Down syndrome is needed to provide the best clinical care.

This narrative review aims to explore currently recognized neuro-ophthalmological manifestations of Down syndrome and discuss the management considerations for the general and the pediatric ophthalmologist, to achieve optimal visual outcomes in these individuals.

\section{Manifestations}

\section{Strabismus and Amblyopia}

Strabismus is reported in up to half of children with Down syndrome. ${ }^{21,22,31-34}$ Esotropia is usually the most frequent type of strabismus, in European and North American populations, varying between $19 \%{ }^{35}$ and $70 \%,{ }^{36}$ while exotropia reportedly occurs in $0 \%{ }^{35,36}$ to $6 \%{ }^{37}$ of cases. In Asians, exotropia is more prevalent, accounting for a third of all types of strabismus encountered in Down syndrome. $^{38}$

Esotropia is usually acquired rather than congenital, and factors such as hyperopia and hypoaccommodative ability are considered important contributors to the development of strabismus. ${ }^{32}$ In children with Down syndrome, acquired esotropia may be associated with lower levels of hyperopia than in the general population. ${ }^{32}$ The hypoaccommodative ability, often present in children with Down syndrome, ${ }^{26,29,39-41}$ leads to an increased accommodative effort which may precipitate the onset of near esotropia. ${ }^{32}$ While also encountered in non-strabismic children with Down syndrome, hypoaccommodation is associated with hyperopia and strabismus in this group. ${ }^{42}$ Weak fusional capacity and dysfunctions in accommodation and convergence may also predispose children with Down syndrome to strabismus. ${ }^{21}$

Ljubic and colleagues reported amblyopia in almost $20 \%$ of 56 children and young adults with Down syndrome, aged between 2 and 28 years old. ${ }^{33}$ Despite the high prevalence of acquired accommodative esotropia, children with Down syndrome seem to have potential for binocular vision with stereopsis present in almost half of this group. ${ }^{32}$ A later age of onset of strabismus, refractive correction and the intermittent nature of esotropia may explain good binocularity in some children with Down syndrome and acquired esotropia.
Infantile esotropia, defined as constant esotropia with an onset before 6 months of age, is less prevalent, and is found in $5 \%$ to $12 \%$ of individuals with Down syndrome. ${ }^{32,33}$

Acquired nonaccommodative esotropia and esotropia with high accommodative-convergence ratios in myopic patients are also frequently found in children with Down syndrome. $^{22}$

\section{Refractive Errors and Failure to Emmetropize}

High incidence of refractive errors and deficits of emmetropization have been found in people with Down syndrome. ${ }^{34,35,39,43-45}$ Oblique astigmatism seems to be the most common refractive error in children with Down syndrome, ${ }^{34,45,46}$ and irregular astigmatism may be an indicator of keratoconus. Clinical keratoconus has been associated with Down syndrome in some studies. ${ }^{31,47,48}$ However, using more sensitive corneal topographic methods, a study of 112 patients with Down syndrome aged between 3 months and 60 years found that up to $75 \%$ of individuals with Down syndrome have corneal irregularities compatible with subclinical and clinical keratoconus. ${ }^{49}$ Anomalies in collagen VI formation induced by overexpression of genes on chromosome $21^{50}$ and the habit of eye rubbing could explain the high incidence of corneal abnormalities in Down syndrome.

Spherical equivalent measures of hyperopia and myopia vary with age and ethnicity and are linearly related to axial length and corneal curvature. ${ }^{48,51}$ In Asians, similar to the refractive errors encountered in the general population, myopia occurs more frequently in those affected by Down syndrome, ${ }^{38}$ while in Caucasian children with Down syndrome, hyperopia is more common. ${ }^{21,22}$ High myopia is reportedly associated with the presence of congenital heart defects, based on a study of 185 children and young adults with Down syndrome. ${ }^{52}$ However, we were unable to confirm this association in a smaller sample of children with Down syndrome. ${ }^{34}$

In addition to refractive error, children with Down syndrome may also have higher-order aberrations of refraction with impact on central optical quality. ${ }^{53}$

A failure to emmetropize is characterized by abnormal axial growth of the ocular globe, in which hyperopia remains stable, while myopia progresses towards pathological values. This deficit is often encountered in children 
with Down syndrome $e^{48,54}$ and leads to persistent refractive error later in life.

\section{Nystagmus}

An estimated $18 \%-30 \%$ of children with Down syndrome reportedly have some form of nystagmus. ${ }^{22,34,55}$ The cause of increased prevalence of this condition in individuals with Down syndrome is not yet fully understood. The nystagmus is mainly latent and latent-manifest, and it is commonly associated with esotropia. ${ }^{34,56}$

Weiss and colleagues studied 18 children with Down syndrome aged between 4 months and 15 years, with nystagmus unrelated to strabismus and proposed neurological abnormalities as substrate for their nystagmus. ${ }^{57}$ However, neuroimaging did not reveal any progressive neurological processes or anatomical brain anomalies to support this hypothesis. ${ }^{58}$

Nystagmus may be of sensory origin in individuals with impaired visual acuity. Various factors such as uncorrected high myopia, congenital dense lens opacities, or amblyopia can diminish visual acuity in children with Down syndrome and lead to sensory nystagmus.

Although optical coherence tomography studies are rare in children with Down syndrome due to poor cooperation, using this technique O'Brien and colleagues reported increased retinal macular thickness in 5 out of 17 children with Down syndrome, aged between 6 and 16 years. ${ }^{59}$ These findings are supported by other recent optical coherence tomography findings that children with Down syndrome have abnormal development of foveal morphology ${ }^{60}$ or an increased retinal thickness. ${ }^{61}$ Thus, mild foveal hypoplasia could contribute to decreased visual acuity and sensory nystagmus in some children with Down syndrome. Further, Laguna and colleagues and Ugurlu and colleagues, with the aid of optical coherence tomography, found increased thickness of the neural retina in individuals with Down syndrome as well as in the trisomic mouse model, probably due to genetic influences on retinal development. ${ }^{61,62}$

\section{Hypoaccommodation}

Accommodation is the capacity of the eye to change focus to enable clear vision at near. ${ }^{26}$ Numerous studies have reported accommodation deficits in individuals with Down syndrome. ${ }^{26,29,39-41}$ Figure 1A shows a 11-year-old boy with myopia and hypoaccommodation wearing his bifocal spectacles, and B illustrates the accommodation evaluation by dynamic retinoscopy. A parent provided written informed consent for the images to be published. Hypoaccommodation was thought to be caused by premature ageing of the lens, ${ }^{29}$ as Down syndrome is associated with greatly increased risk of congenital as presenile cataracts. ${ }^{12,21,63,64}$ Congenital cases of cataract may be due to abnormalities of the vascular system during embryological development. ${ }^{19}$ However, most children with Down syndrome do not have significant lens opacities, ${ }^{21}$ the frequencies of significant congenital and early age cataracts in Down syndrome being $1 \%$ and $1.4 \%$, respectively. ${ }^{65}$

After adolescence, about half of individuals with Down syndrome have some form of notable lens opacity, due in most cases to an accumulation of amyloid precursor protein (APP)-derived amyloid-beta peptides, ${ }^{66}$ with visually significant cataract developing at a much earlier age compared to the general population. ${ }^{21,64}$ Figure 1D illustrates a blue dot cataract in a 16-year-old boy with Down syndrome.

However, not all children with lens opacities have accommodation deficits, ${ }^{42}$ and lens thickness and power are reportedly similar in people with Down syndrome with and without hypoaccommodation. ${ }^{51}$ The neurological and/ or muscular basis of hypoaccommodation in Down syndrome is yet to be established and constitutes a further area for investigation. ${ }^{67}$

However, it is understood that poor accommodation ability is associated with hyperopia and strabismus in children with Down syndrome ${ }^{68}$ and that hypoaccommodation contributes to reduced visual acuity due to poor near focus and bilateral amblyopia. ${ }^{39}$

\section{Optic Nerve Anomalies}

An increased number of blood vessels crossing the optic disc margin is a commonly noted anomaly of the posterior segment of the eye in Down syndrome..$^{21,69-71}$ Parsa and Almer suggested that the retinal vasculature is not increased in absolute value; rather, retinal vessels radiating from the disc center branch slightly earlier, before reaching the optic disc margin, and hence "crowd" the papillae. This could be due to reduced expansion of the central optic disc hyaloid vessel during its transformation to central retinal vasculature as a result of a mild deficiency in angiogenesis. ${ }^{71}$ Figure $2 \mathrm{~A}$ shows a small, crowded papilla with supernumerary vessels crossing the optic disc margin, in a child with Down syndrome.

Optic nerve hypoplasia, elevation, pallor, crescents, tilted discs, peripapillary atrophy, and pigment anomalies 


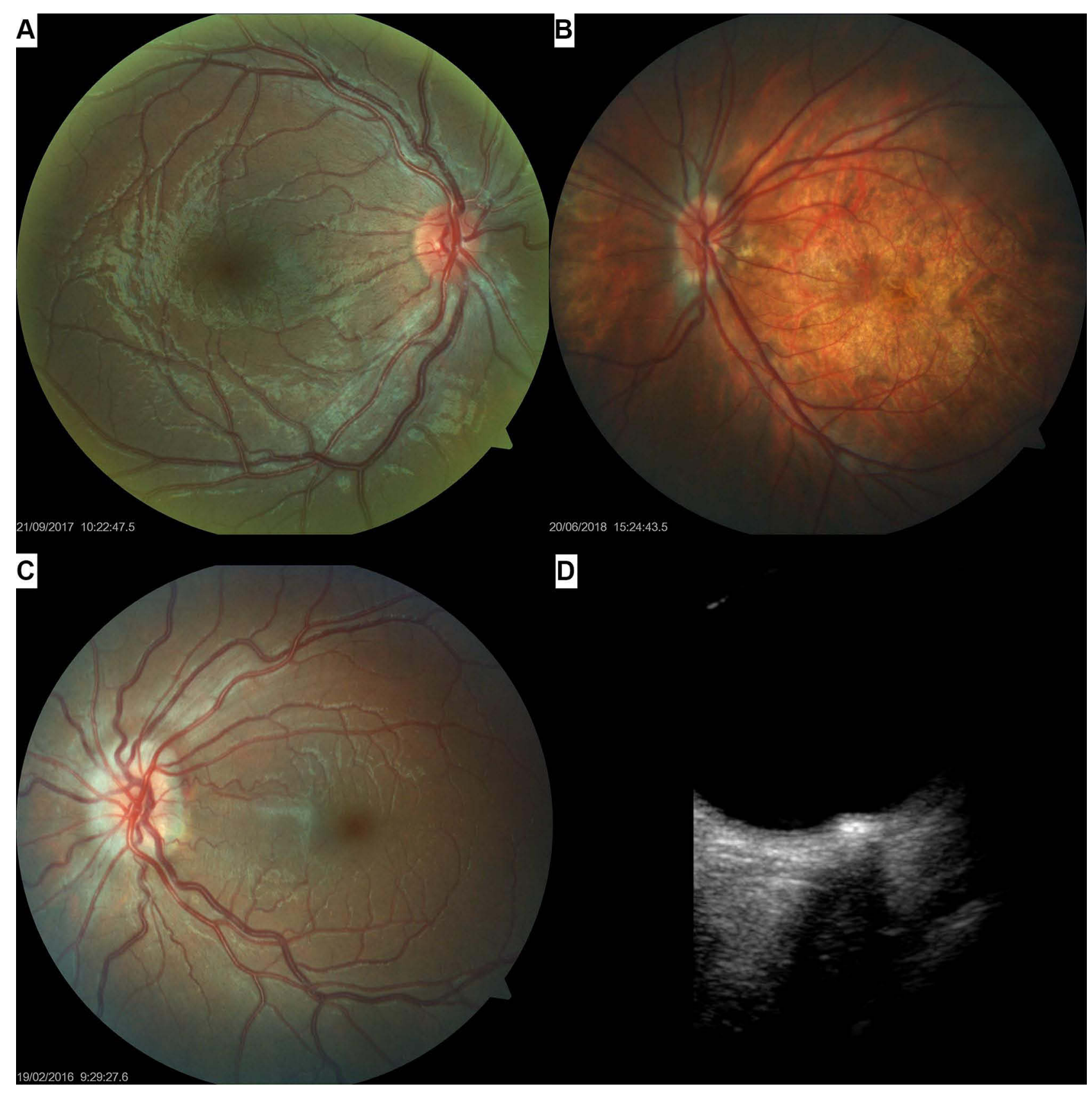

Figure 2 Optic nerve anomalies in Down syndrome. (A) Small, crowded papilla with an increased number of vessels crossing the optic disc margin, in an II year old boy with Down syndrome. (B) Posterior segment photograph of a 13 year old boy with Down syndrome, high myopia, tilted disc, tessellated fundus and posterior pole staphyloma. (C) Fundus imaging showing an optic disc drusen in a 16 year girl with Down syndrome. (D) The aspect of the drusen in the same eye as seen with B-scan ultrasonography.

have been sporadically described in some studies and case reports. ${ }^{19,72-82}$ Schneier and colleagues retrospectively analyzed optic nerve head appearance in a large series of 806 children with Down syndrome and found $14 \%$ to be abnormal. ${ }^{83}$ Optic nerve hypoplasia and the presence of a double ring sign in individuals with Down syndrome have been occasionally reported in the literature. ${ }^{72,73,84-86}$
In a study based on fundus photographs of 50 children with Down syndrome (mean age $9.8 \pm 3.8$ years) and of 52 typically developing children (mean age $7.6 \pm 3.0$ years), we confirmed that optic discs were smaller in children with Down syndrome than in controls, and in some cases, a mild optic disc hypoplasia was present. ${ }^{34}$ Absence of the physiological cup was observed in almost half of the images, while $8 \%$ showed a double ring 
sign. These findings are both indirect signs of a small optic nerve head.

The optic nerve head also more frequently appeared tilted, torted, or featured a crescent or pigment anomaly. ${ }^{34}$ While in the general population, these anomalies are often related to refraction, especially myopia and astigmatism, ${ }^{87,88}$ in children with Down syndrome this spectrum of optic nerve head anomalies was unrelated to refractive errors. ${ }^{34}$ Figure $2 \mathrm{~B}$ illustrates the ocular posterior segment of a 13-year-old boy with Down syndrome, high myopia, tilted disc, tessellated fundus and posterior pole staphyloma.

Optic disc elevation has been linked to Down syndrome and may be either pseudo $^{75,77}$ or true papilledema. $^{74}$

Optic disc drusen has been reported in some series and case reports on people with Down syndrome. ${ }^{34,83,89}$ B-scan ultrasonography has been particularly useful in the differential diagnosis of papilledema, as some of the comorbidities of Down syndrome, such as obesity or hypothyroidism, are risk factors for intracranial pressure. ${ }^{74}$ An optic disc drusen in a girl with Down syndrome is illustrated in Figure 2 (C: fundus imaging and D: B-scan ultrasonography).

Small optic disc size, a lack of physiological cupping and crowded vasculature might constitute risk factors for drusen accumulation at the optic nerve head in individuals with Down syndrome. ${ }^{34,90}$

Other optic nerve anomalies such as morning glory, ${ }^{91,92}$ optic nerve coloboma, ${ }^{93}$ optic nerve glioma, ${ }^{94}$ optic nerve pit $^{82}$ and optic nerve atrophy ${ }^{43}$ have been sporadically reported in the literature and may represent coincidental findings.

\section{Visual Acuity in Children with Down Syndrome}

Compared to their peers without Down syndrome, children with Down syndrome have decreased visual acuity. ${ }^{26,27}$ Such reduction in recorded visual acuity may reflect ocular comorbidities such as accommodative deficiency, strabismus or refractive errors, anterior and posterior segment anomalies or simply a lack of patient cooperation during subjective visual acuity testing.

Anterior segment ocular anomalies which may affect the visual acuity include keratoconus and lens opacities.

Posterior segment anomalies are less frequently described and consist of retinal anomalies, including hemorrhage, ${ }^{79,95}$ coloboma,$~^{76}$ retinal detachment, ${ }^{22,42,43,76}$ retinal arterial embolism, ${ }^{27}$ and congenital stationary night blindness. ${ }^{76}$ While retinal detachment could be due to a higher risk of ocular trauma in patients with intellectual disabilities, the other retinal anomalies probably represent sporadic findings and are not specifically associated with the syndrome.

Tessellated fundi are more often encountered in children with Down syndrome than in controls, and are unrelated to the presence of myopia, but are not a cause for decreased visual acuity in these individuals. ${ }^{45}$

We have previously shown an association between nystagmus (horizontal and either latent-manifest or manifest) and reduced vision in children with Down syndrome. ${ }^{34}$ Although the causes of nystagmus in Down syndrome are not fully understood, ${ }^{57,96,97}$ this condition is more likely to be a consequence of impaired vision than a cause of it. Even in children with Down syndrome with no apparent ocular anomalies, visual acuity test performance is often lower than in typically developing children. ${ }^{27}$ Woodhouse and colleagues reported normal visual acuity in children with Down syndrome under two years of age, with deviation from the normal after this age, ${ }^{26}$ while earlier work by Courage et al showed deviation from the normal after the age of 6 months. ${ }^{27}$ Recently, Zahidi and colleagues found visual acuity below normal levels in children with Down syndrome from three to four years of age and provided reference values for binocular vision in this group up to 12 years of age. ${ }^{98}$ In addition, measures of contrast sensitivity ${ }^{99}$ and visual evoked potentials $^{100}$ may be abnormal in children with Down syndrome; such findings could potentially be due to difficulties in obtaining full concentration in these children.

Visual deficits encountered in Down syndrome may in part have a cortical basis. The brain in Down syndrome is globally reduced in volume, ${ }^{101}$ mostly due to fewer differentiated neurons in the prefrontal cortex, hippocampus, parahippocampal gyrus and cerebellum than in controls. ${ }^{101-103}$ This is observed early in fetal life, and further decreases in brain size continue postnatally. ${ }^{104} \mathrm{As}$ individuals age, brain atrophy compounds pre-existing development anomalies. ${ }^{105}$

The dendritic structures that constitute the neuronal synapses are also reduced in length and show less branching in the hippocampus and cortex in Down syndrome. ${ }^{106-109}$ Beyond gross brain structural anomalies, at a molecular level protein encoded by the Down syndrome critical region on the long arm of chromosome 21 contribute to neurodegeneration 
and impaired synaptic function. ${ }^{110,111}$ Further research on brain structure centered on the visual cortex is needed to determine the impact of brain anomalies upon visual acuity.

\section{Diagnosis and Management}

Due to the high prevalence of ocular comorbidities, the ophthalmologist plays an essential role, together with a multidisciplinary team, in the medical care of children with Down syndrome. Each child with Down syndrome would benefit from a neonatal visual screening in order to exclude a potentially blinding congenital cataract ${ }^{65}$ and a routine ophthalmological examination at least once per year. In typically developing children, school screening is usually performed prior to specific ophthalmological examination. However, the reliability of photoscreening in children with Down syndrome is lower than in other children ${ }^{112}$ highlighting the importance of adequate ocular examination in this population, ideally performed by an experienced pediatric ophthalmologist.

Purpura and colleagues examined very young children with Down syndrome, aged between 6 and 18 months, using Teller Acuity Cards and found a correlation between visual acuity and ocular anomalies at this age. ${ }^{113}$ If detected early, anomalies such as cataracts, strabismus, refractive errors, and amblyopia may be managed before developing adverse sequelae. ${ }^{114}$

Refractive correction, especially the use of bifocal spectacles in those children with hypoaccommodation or accommodative esotropia, may not only compensate for inaccurate accommodation, ${ }^{115,116}$ but also ameliorate associated strabismus. ${ }^{117}$

Children with Down syndrome and esotropia or exotropia should be offered surgical correction when needed.

The surgical treatment for esotropia in Down syndrome is highly effective, with no need to adjust the surgery dosage recommended for typically developing children. ${ }^{118,119}$ The success rate after classical surgical procedures is reported to be between 66 and $90 \%{ }^{37,120-122}$

Visual acuity and accommodation tests, suitably adapted for intellectual level, will allow amblyopia to be detected then treated, and therefore improve visual outcomes in children with Down syndrome.

A careful assessment of the anterior and posterior segment of the eye would allow the treatment of potentially blinding ocular comorbidities such as cataract, keratoconus, retinal detachment or papilledema due to increased intracranial pressure.

\section{Limitations}

This narrative review lacks systematic study selection and analysis. However, the authors sought relevant studies and attempted to maintain a neutral viewpoint throughout.

\section{Conclusion}

This review summarizes the major ocular anomalies encountered in Down syndrome with emphasis on neuroophthalmological manifestations. Most of these ocular and neuro-ophthalmological problems may lead to decreased visual acuity.

Individuals with cognitive and visual impairment report greater difficulties in performing daily activities than those with cognitive impairment alone. As children with Down syndrome have social, behavioral and emotional difficulties, visual impairment significantly reduces their overall quality of life. ${ }^{24}$ Therefore, the pediatric ophthalmologist must strive to provide the best advice and intervention for improved visual acuity and to minimize ocular complications in all children with Down syndrome. Further, parents and teachers must be aware that despite refractive correction children with Down syndrome may have poor visual acuity, which may lead to failure in performing intellectual tasks and be erroneously attributed to their cognitive impairment.

\section{Disclosure}

The authors report no conflicts of interest in this work.

\section{References}

1. Weijerman ME, van Furth AM, Vonk Noordegraaf A, van Wouwe JP, Broers CJ, Gemke RJ. Prevalence, neonatal characteristics, and first-year mortality of Down syndrome: a national study. J Pediatr. 2008;152(1):15-19. doi:10.1016/j.jpeds.2007.09.045

2. Contestabile A, Benfenati F, Gasparini L. Communication breaks-Down: from neurodevelopment defects to cognitive disabilities in Down syndrome. Prog Neurobiol. 2010;91(1):1-22.

3. Ait Yahya-Graison E, Aubert J, Dauphinot L, et al. Classification of human chromosome 21 gene-expression variations in Down syndrome: impact on disease phenotypes. Am J Hum Genet. 2007;81 (3):475-491. doi:10.1086/520000

4. Roper RJ, Reeves RH. Understanding the basis for Down syndrome phenotypes. PLoS Genet. 2006;2(3):e50. doi:10.1371/journal. pgen.0020050

5. Antonarakis SE. Down syndrome and the complexity of genome dosage imbalance. Nat Rev Genet. 2017;18(3):147-163. doi:10.1038/ nrg.2016.154

6. Roper RJ, St John HK, Philip J, Lawler A, Reeves RH. Perinatal loss of Ts65Dn Down syndrome mice. Genetics. 2006;172(1):437-443. doi:10.1534/genetics.105.050898

7. Halliday J, Collins V, Riley M, Youssef D, Muggli E. Has prenatal screening influenced the prevalence of comorbidities associated with Down syndrome and subsequent survival rates? Pediatrics. 2009;123 (1):256-261. doi:10.1542/peds.2007-2840 
8. Rankin J, Tennant PW, Bythell M, Pearce MS. Predictors of survival in children born with Down syndrome: a registry-based study. Pediatrics. 2012;129(6):e1373-1381. doi:10.1542/ peds.2011-3051

9. Morris JK, Garne E, Wellesley D, et al. Major congenital anomalies in babies born with Down syndrome: a EUROCAT population-based registry study. Am J Med Genet A. 2014;164a (12):2979-2986. doi:10.1002/ajmg.a.36780

10. Stoll C, Dott B, Alembik Y, Roth MP. Associated congenital anomalies among cases with Down syndrome. Eur J Med Genet. 2015;58(12):674-680. doi:10.1016/j.ejmg.2015.11.003

11. van der Linde D, Konings EE, Slager MA, et al. Birth prevalence of congenital heart disease worldwide: a systematic review and meta-analysis. J Am Coll Cardiol. 2011;58(21):2241-2247. doi:10.1016/j.jacc.2011.08.025

12. Torfs CP, Christianson RE. Anomalies in Down syndrome individuals in a large population-based registry. Am J Med Genet. 1998;77(5):431-438. doi:10.1002/(SICI)1096-8628(19980605) 77:5<431::AID-AJMG15>3.0.CO;2-J

13. Head E, Lott IT, Wilcock DM, Lemere CA. Aging in Down Syndrome and the Development of Alzheimer's Disease Neuropathology. Curr Alzheimer Res. 2016;13(1):18-29. doi:10.2174/1567205012666151020114607

14. Lima FA, Moreira-Filho CA, Ramos PL, et al. Decreased AIRE expression and global thymic hypofunction in Down syndrome. J Immunol. 2011;187(6):3422-3430. doi:10.4049/jimmunol.1 003053

15. Kennedy RL, Jones TH, Cuckle HS. Down's syndrome and the thyroid. Clin Endocrinol. 1992;37(6):471-476. doi:10.1111/ j.1365-2265.1992.tb01475.x

16. Karlsson B, Gustafsson J, Hedov G, Ivarsson SA, Anneren G. Thyroid dysfunction in Down's syndrome: relation to age and thyroid autoimmunity. Arch Dis Child. 1998;79(3):242-245. doi:10.1136/adc.79.3.242

17. Hawli Y, Nasrallah M, El-Hajj Fuleihan G. Endocrine and musculoskeletal abnormalities in patients with Down syndrome. Nat Rev Endocrinol. 2009;5(6):327-334. doi:10.1038/nrendo.2009.80

18. Pierce MJ, LaFranchi SH, Pinter JD. Characterization of Thyroid Abnormalities in a Large Cohort of Children with Down Syndrome. Horm Res in Paediatr. 2017;87(3):170-178. doi:10.1159/000457952

19. Lowe RF. The eyes in mongolism. Br J Ophthalmol. 1949;33 (3):131-174. doi:10.1136/bjo.33.3.131

20. Donaldason DD. The significance of spotting of the iris in Mongolids. Brushfield's spots. Arch Ophthalmol. 1961;65 (1):23-31.

21. Jaeger EA. Ocular findings in Down's syndrome. Trans Am Ophthalmol Soc. 1980;78:808-845.

22. da Cunha RP, Moreira JB. Ocular findings in Down's syndrome. Am J Ophthalmol. 1996;122(2):236-244. doi:10.1016/S00029394(14)72015-X

23. Liza-Sharmini AT, Azlan ZN, Zilfalil BA. Ocular findings in Malaysian children with Down syndrome. Singapore Med J. 2006;47(1):14-19.

24. Akinci A, Oner O, Bozkurt OH, Guven A, Degerliyurt A, Munir K. Refractive errors and strabismus in children with Down syndrome: a controlled study. $J$ Pediatr Ophthalmol Strabismus. 2009;46(2):83-86. doi:10.3928/0191391320090301-04

25. Postolache L, Parsa CF. Brushfield spots and Wolfflin nodules unveiled in dark irides using near-infrared light. Sci Rep. 2018;8 (1):18040. doi:10.1038/s41598-018-36348-6

26. Woodhouse JM, Pakeman VH, Saunders KJ, et al. Visual acuity and accommodation in infants and young children with Down's syndrome. J Intellect Disabil Res. 1996;40(Pt 1):49-55. doi:10.1111/j.1365-2788.1996.tb00602.x
27. Courage ML, Adams RJ, Reyno S, Kwa PG. Visual acuity in infants and children with Down syndrome. Dev Med Child Neurol. 1994;36(7):586-593. doi:10.1111/j.1469-8749.1994. tb11895.x

28. Felius J, Beauchamp CL, Stager DR. Visual acuity deficits in children with nystagmus and Down syndrome. Am J Ophthalmol. 2014;157(2):458-463. doi:10.1016/j.ajo.2013.09.023

29. Woodhouse JM, Meades JS, Leat SJ, Saunders KJ. Reduced accommodation in children with Down syndrome. Invest Ophthalmol Vis Sci. 1993;34(7):2382-2387.

30. Creavin AL, Brown RD. Ophthalmic abnormalities in children with Down syndrome. J Pediatr Ophthalmol Strabismus. 2009;46 (2):76-82.

31. Shapiro MB, France TD. The ocular features of Down's syndrome. Am J Ophthalmol. 1985;99(6):659-663. doi:10.1016/ S0002-9394(14)76031-3

32. Haugen $\mathrm{OH}$, Hovding G. Strabismus and binocular function in children with Down syndrome. A population-based, longitudinal study. Acta Ophthalmol Scand. 2001;79(2):133-139. doi:10.1034/ j.1600-0420.2001.079002133.x

33. Ljubic A, Trajkovski V, Stankovic B. Strabismus, refractive errors and nystagmus in children and young adults with Down syndrome. Ophthalmic Genet. 2011;32(4):204-211. doi:10.3109/ 13816810.2011.592175

34. Postolache L. Abnormalities of the optic nerve in Down syndrome and associations with visual acuity. Front Neurol. 2019;10:633. doi:10.3389/fneur.2019.00633

35. Woodhouse JM, Pakeman VH, Cregg M, et al. Refractive errors in young children with Down syndrome. Optom Vis Sci. 1997;74 (10):844-851. doi:10.1097/00006324-199710000-00023

36. Rochels R, Nover A, Schmid F. Ophthalmologic symptoms of Down's syndrome (author's transl). Graefes Arch Clin Exp Ophthalmol. 1977;205(1):9-12. doi:10.1007/BF00413458

37. Hiles DA, Hoyme SH, McFarlane F. Down's syndrome and strabismus. Am Orthopt J. 1974;24:63-68. doi:10.1080/ 0065955X.1974.11982348

38. Kim U, Hwang JM. Refractive errors and strabismus in Asian patients with Down syndrome. Eye. 2009;23(7):1560-1564. doi:10.1038/eye.2008.309

39. Cregg M, Woodhouse JM, Pakeman VH, et al. Accommodation and refractive error in children with Down syndrome: cross-sectional and longitudinal studies. Invest Ophthalmol Vis Sci. 2001;42(1):55-63.

40. Doyle L, Saunders KJ, Little JA. Trying to see, failing to focus: near visual impairment in Down syndrome. Sci Rep. 2016;6:20444. doi:10.1038/srep20444

41. Doyle L, Saunders KJ, Little JA. Determining the relative contribution of retinal disparity and blur cues to ocular accommodation in Down syndrome. Sci Rep. 2017;7:39860. doi:10.1038/ srep39860

42. Stewart RE, Woodhouse JM, Cregg M, Pakeman VH. Association between accommodative accuracy, hypermetropia, and strabismus in children with Down's syndrome. Optom Vis Sci. 2007;84 (2):149-155. doi:10.1097/OPX.0b013e318031b686

43. Berk AT, Saatci AO, Ercal MD, Tunc M, Ergin M. Ocular findings in 55 patients with Down's syndrome. Ophthalmic Genet. 1996;17(1):15-19. doi:10.3109/13816819609057864

44. Cregg M, Woodhouse JM, Stewart RE, et al. Development of refractive error and strabismus in children with Down syndrome. Invest Ophthalmol Vis Sci. 2003;44(3):1023-1030. doi:10.1167/ iovs.01-0131

45. Postolache L, De Jong C, Casimir G. Illustration of tessellation in Down syndrome. Ophthalmic Genet. 2020;2:1-11.

46. Ljubic A, Trajkovski V. Refractive errors in children and young adults with Down's syndrome. Acta Ophthalmol. 2011;89 (4):324-327. doi:10.1111/j.1755-3768.2009.01676.x 
47. Walsh SZ. Keratoconus and blindness in 469 institutionalised subjects with Down syndrome and other causes of mental retardation. J Ment Defic Res. 1981;25(Pt 4):243-251.

48. Doyle SJ, Bullock J, Gray C, Spencer A, Cunningham C. Emmetropisation, axial length, and corneal topography in teenagers with Down's syndrome. Br J Ophthalmol. 1998;82 (7):793-796. doi:10.1136/bjo.82.7.793

49. Alio JL, Vega-Estrada A, Sanz P, et al. Corneal Morphologic Characteristics in Patients With Down Syndrome. JAMA Ophthalmol. 2018;136(9):971-978. doi:10.1001/ jamaophthalmol.2018.2373

50. Karousou E, Stachtea X, Moretto P, et al. New insights into the pathobiology of Down syndrome-hyaluronan synthase-2 overexpression is regulated by collagen VI alpha2 chain. FEBS J. 2013;280(10):2418-2430. doi:10.1111/febs.12220

51. Haugen $\mathrm{OH}$, Høvding G, Eide GE. Biometric measurements of the eyes in teenagers and young adults with Down syndrome. Acta Ophthalmol Scand. 2001;79(6):616-625. doi:10.1034/ j.1600-0420.2001.790613.x

52. Ljubic A, Trajkovski V, Tesic M, Tojtovska B, Stankovic B. Ophthalmic manifestations in children and young adults with Down syndrome and congenital heart defects. Ophthalmic Epidemiol. 2015;22(2):123-129. doi:10.3109/09286586.2015.1017652

53. McCullough SJ, Little JA, Saunders KJ. Higher order aberrations in children with Down syndrome. Invest Ophthalmol Vis Sci. 2013;54(2):1527-1535. doi:10.1167/iovs.12-10597

54. Haugen $\mathrm{OH}$, Hovding $\mathrm{G}$, Lundstrom I. Refractive development in children with Down's syndrome: a population based, longitudinal study. $\quad B r \quad J$ Ophthalmol. 2001;85(6):714-719. doi:10.1136/ bjo.85.6.714

55. Wagner RS, Caputo AR, Reynolds RD. Nystagmus in Down's syndrome. Ophthalmology. 1990;97(11):1439-1444. doi:10.1016/ S0161-6420(90)32399-0

56. Averbuch-Heller L, Dell'Osso LF, Jacobs JB, Remler BF. Latent and congenital nystagmus in Down syndrome. J Neuroophthalmol. 1999;19(3):166-172. doi:10.1097/ 00041327-199909000-00003

57. Weiss AH, Kelly JP, Phillips JO. Infantile Nystagmus and Abnormalities of Conjugate Eye Movements in Down Syndrome. Invest Ophthalmol Vis Sci. 2016;57(3):1301-1309. doi:10.1167/iovs.15-18532

58. Wong MM, Schneier AJ, Ledoux D, Heidary G. Neuroimaging Findings in Patients With Down Syndrome and Nystagmus. $J$ AAPOS. 2016;53(6):383

59. O'Brien S, Wang J, Smith HA, et al. Macular structural characteristics in children with Down syndrome. Graefes Arch Clin Exp Ophthalmol. 2015;253(12):2317-2323. doi:10.1007/s00417-015-3088-x

60. Mangalesh S, Vinekar A, Jayadev C, et al. Spectral Domain Optical Coherence Tomography in Detecting Sub-Clinical Retinal Findings in Asian Indian Children with Down Syndrome. Curr Eye Res. 2019;1:1-7.

61. Ugurlu A, Altinkurt E. Ophthalmologic Manifestations and Retinal Findings in Children with Down Syndrome. J Ophthalmol. 2020;2020:9726261. doi:10.1155/2020/9726261

62. Laguna A, Barallobre MJ, Marchena MA, et al. Triplication of DYRK1A causes retinal structural and functional alterations in Down syndrome. Hum Mol Genet. 2013;22(14):2775-2784. doi:10.1093/hmg/ddt125

63. Cleves MA, Hobbs CA, Cleves PA, Tilford JM, Bird TM, Robbins JM. Congenital defects among liveborn infants with Down syndrome. Birth Defects Res a Clin Mol Teratol. 2007;79 (9):657-663. doi:10.1002/bdra.20393

64. Krinsky-McHale SJ, Jenkins EC, Zigman WB, Silverman W. Ophthalmic disorders in adults with down syndrome. Curr Gerontol Geriatr Res. 2012;2012:974253. doi:10.1155/2012/ 974253
65. Haargaard B, Fledelius HC. Down's syndrome and early cataract. $\mathrm{Br} J$ Ophthalmol. 2006;90(8):1024-1027. doi:10.1136/ bjo.2006.090639

66. Moncaster JA, Pineda R, Moir RD, et al. Alzheimer's disease amyloid-beta links lens and brain pathology in Down syndrome. PLoS One. 2010;5(5):e10659. doi:10.1371/journal.pone.0010659

67. Roche O, Roumes C, Parsa C. Techniques for measuring phakic and pseudophakic accommodation. Methodology for distinguishing between neurological and mechanical accommodative insufficiency. J Fr Ophtalmol. 2007;30(9):953-960. doi:10.1016/ S0181-5512(07)74039-1

68. Woodhouse JM, Cregg M, Gunter HL, et al. The effect of age, size of target, and cognitive factors on accommodative responses of children with Down syndrome. Invest Ophthalmol Vis Sci. 2000;41(9):2479-2485.

69. Williams EJ, McCormick AQ, Tischler B. Retinal vessels in Down's syndrome. Arch Ophthalmol. 1973;89(4):269-271. doi:10.1001/archopht.1973.01000040271001

70. Sherk MC, Williams TD. Disc vascularity in Down's syndrome. Am J Optom Physiol Opt. 1979;56(8):509-511. doi:10.1097/ 00006324-197908000-00005

71. Parsa CF, Almer Z. Supranumerary optic disc vessels may indicate reduced systemic angiogenesis in Down syndrome. $\mathrm{Br}$ J Ophthalmol. 2008;92(3):432-433. doi:10.1136/bjo.2007.124248

72. Fierson WM. Ophthalmological aspects. In: Van Dyke DLD, Heide F, Van Duyne S, Soucek M, editors. Clinical Perspectives in the Management of Down's Syndrome. Disorders of Human Learning, Behavior, and Communication. New-York: Springer; 1990:26-54.

73. Awan KJ. Uncommon ocular changes in Down's syndrome (mongolism). J Pediatr Ophthalmol. 1977;14(4):215-216.

74. Esmaili N, Bradfield YS. Pseudotumor cerebri in children with Down syndrome. Ophthalmol. 2007;114(9):1773-1778. doi:10.1016/j.ophtha.2006.12.015

75. Al-Hemidan AI, Al-Hazzaa SA, Chavis P, Al-Hussein H. Optic disc elevation in Down syndrome. Ophthalmic Genet. 1999;20 (1):45-51. doi:10.1076/opge.20.1.45.2297

76. Roizen NJ, Mets MB, Blondis TA. Ophthalmic disorders in children with Down syndrome. Dev Med Child Neurol. 1994;36 (7):594-600. doi:10.1111/j.1469-8749.1994.tb11896.x

77. Catalano RA, Simon JW. Optic disk elevation in Down's syndrome. Am J Ophthalmol. 1990;110(1):28-32. doi:10.1016/ S0002-9394(14)76933-8

78. Stirn Kranjc B. Ocular abnormalities and systemic disease in Down syndrome. Strabismus. 2012;20(2):74-77. doi:10.3109/ 09273972.2012.680234

79. Fimiani F, Iovine A, Carelli R, Pansini M, Sebastio G, Magli A. Incidence of ocular pathologies in Italian children with Down syndrome. Eur J Ophthalmol. 2007;17(1):817-822. doi:10.1177 112067210701700521

80. Wagner RS. Ocular genetics and Down syndrome. J Pediatr Ophthalmol Strabismus. 2009;46(2):75. doi:10.3928/0191391320090301-09

81. Ahmad A, Pruett RC. The Fundus in Mongolism. Arch Ophthalmol. 1976;94(5):772-776. doi:10.1001/ archopht.1976.03910030378005

82. Fong AH, Shum J, Ng AL, Li KK, McGhee S, Wong D. Prevalence of ocular abnormalities in adults with Down syndrome in Hong Kong. $\mathrm{Br} J$ Ophthalmol. 2013;97(4):423-428. doi:10.1136/bjophthalmol-2012-302327

83. Schneier AJ, Heidary G, Ledoux DM. Optic nerve appearance in patients with Down syndrome. J Pediatr Ophthalmol Strabismus. 2013;50(1):60. doi:10.3928/01913913-20121214-01

84. Ginsberg J, Bofinger MK, Roush JR. Pathologic features of the eye in Down's syndrome with relationship to other chromosomal anomalies. Am J Ophthalmol. 1977;83(6):874-880. doi:10.1016/ 0002-9394(77)90918-7 
85. Ginsberg J, Ballard ET, Buchino JJ, Kinkler AK. Further observations of ocular pathology in Down's syndrome. J Pediatr Ophthalmol Strabismus. 1980;17(3):166-171. doi:10.3928/01913913-19800501-10

86. Mansour AM, Bitar FF, Traboulsi EI, et al. Ocular pathology in congenital heart disease. Eye. 2005;19(1):29-34. doi:10.1038/sj. eye. 6701408

87. Young SE, Walsh FB, Knox DL. The tilted disk syndrome. Am $J$ Ophthalmol. 1976;82(1):16-23. doi:10.1016/0002-9394(76) 90658-9

88. Guo Y, Liu LJ, Xu L, et al. Optic Disc Ovality in Primary School Children in Beijing. Invest Ophthalmol Vis Sci. 2015;56 (8):4547-4553. doi:10.1167/iovs.15-16590

89. Kamoun R, Mili Boussen I, Beltaief O, Ouertani A. Drusen in children: three case studies. $J$ Fr Ophtalmol. 2008;31(1):e1.

90. Mullie MA, Sanders MD. Scleral canal size and optic nerve head drusen. Am J Ophthalmol. 1985;99(3):356-359. doi:10.1016/ 0002-9394(85)90369-1

91. Altun A, Altun G, Kurna SA, Olcaysu OO, Aki SF. Unilateral morning glory optic disc anomaly in a case with Down syndrome. BMC Ophthalmol. 2014;14:48. doi:10.1186/1471-2415-14-48

92. Biskin FDY, Altin M. Ocular findings in the patients with Down syndrome. Turkiye Klinikleri J Ophthalmol. 2005;1(14):17-24.

93. De Souza CF, Berbigier GA, Costa F, Ruschel SP, Silva T, Schuler L. Optic nerve coloboma in Down syndrome. Clin Dysmorphol. 1995;4(2):176-177. doi:10.1097/00019605199504000-00012

94. Jonakin WL, Hensley MF. Optic glioma and Down's syndrome. $J$ Am Osteopath Assoc. 1983;82(11):806.

95. Stephen E, Dickson J, Kindley AD, Scott CC, Charleton PM. Surveillance of vision and ocular disorders in children with Down syndrome. Dev Med Child Neurol. 2007;49(7):513-515. doi:10.1111/j.1469-8749.2007.00513.x

96. Costa AC. An assessment of optokinetic nystagmus (OKN) in persons with Down syndrome. Exp Brain Res. 2011;214 (3):381-391. doi:10.1007/s00221-011-2834-5

97. Costa AC. An assessment of the vestibulo-ocular reflex (VOR) in persons with Down syndrome. Exp Brain Res. 2011;214 (2):199-213. doi:10.1007/s00221-011-2820-y

98. Zahidi AA, Vinuela-Navarro V, Woodhouse JM. Different visual development: norms for visual acuity in children with Down's syndrome. Clin Exp Optom. 2018;101(4):535-540. doi:10.1111/cxo.12684

99. Courage ML, Adams RJ, Hall EJ. Contrast sensitivity in infants and children with Down syndrome. Vision Res. 1997;37 (11):1545-1555. doi:10.1016/S0042-6989(96)00304-5

100. John FM, Bromham NR, Woodhouse JM, Candy TR. Spatial vision deficits in infants and children with Down syndrome. Invest Ophthalmol Vis Sci. 2004;45(5):1566-1572. doi:10.1167/ iovs.03-0951

101. Wisniewski KE. Down syndrome children often have brain with maturation delay, retardation of growth, and cortical dysgenesis. Am J Med Genet Supp. 1990;7:274-281.

102. Benavides-Piccione R, Ballesteros-Yanez I, de Lagran MM, et al. On dendrites in Down syndrome and DS murine models: a spiny way to learn. Prog Neurobiol. 2004;74(2):111-126. doi:10.1016/j. pneurobio.2004.08.001

103. Wisniewski HM, Silverman W, Wegiel J. Ageing, Alzheimer disease and mental retardation. $J$ Intellect Disabil Res. 1994;38 (Pt 3):233-239. doi:10.1111/j.1365-2788.1994.tb00391.x

104. Pinter JD, Eliez S, Schmitt JE, Capone GT, Reiss AL. Neuroanatomy of Down's syndrome: a high-resolution MRI study. Am J Psychiatry. 2001;158(10):1659-1665. doi:10.1176/ appi.ajp.158.10.1659

105. Teipel SJ, Hampel H. Neuroanatomy of Down syndrome in vivo: a model of preclinical Alzheimer's disease. Behav Genet. 2006;36 (3):405-415. doi:10.1007/s10519-006-9047-x
106. Becker LE, Armstrong DL, Chan F. Dendritic atrophy in children with Down's syndrome. Ann Neurol. 1986;20(4):520-526. doi:10.1002/ana.410200413

107. Takashima S, Iida K, Mito T, Arima M. Dendritic and histochemical development and ageing in patients with Down's syndrome. J Intellect Disabil Res. 1994;38(Pt 3):265-273. doi:10.1111/ j.1365-2788.1994.tb00394.x

108. Takashima S, Ieshima A, Nakamura H, Becker LE. Dendrites, dementia and the Down syndrome. Brain Dev. 1989;11 (2):131-133. doi:10.1016/S0387-7604(89)80082-8

109. Takashima S, Becker LE, Armstrong DL, Chan F. Abnormal neuronal development in the visual cortex of the human fetus and infant with down's syndrome. A quantitative and qualitative Golgi study. Brain Res. 1981;225(1):1-21. doi:10.1016/00068993(81)90314-0

110. Delabar JM, Theophile D, Rahmani Z, et al. Molecular mapping of twenty-four features of Down syndrome on chromosome 21. Eur J Hum Genet. 1993;1(2):114-124. doi:10.1159/000472398

111. Korenberg JR, Chen XN, Schipper R, et al. Down syndrome phenotypes: the consequences of chromosomal imbalance. Proc Natl Acad Sci USA. 1994;91(11):4997-5001. doi:10.1073/ pnas.91.11.4997

112. Yanovitch T, Wallace DK, Freedman SF, et al. The accuracy of photoscreening at detecting treatable ocular conditions in children with Down syndrome. $J$ AAPOS. 2010;14(6):472-477. doi:10.1016/j.jaapos.2010.09.016

113. Purpura G, Bacci GM, Bargagna S, Cioni G, Caputo R, Tinelli F. Visual assessment in Down Syndrome: the relevance of early visual functions. Early Hum Dev. 2019;131:21-28. doi:10.1016/ j.earlhumdev.2019.01.020

114. Watt T, Robertson K, Jacobs RJ. Refractive error, binocular vision and accommodation of children with Down syndrome. Clin Exp Optom. 2015;98(1):3-11. doi:10.1111/cxo.12232

115. Stewart RE, Margaret Woodhouse J, Trojanowska LD. In focus: the use of bifocal spectacles with children with Down's syndrome. Ophthalmic Physiol Opt. 2005;25(6):514-522. doi:10.1111/j.1475-1313.2005.00326.x

116. Al-Bagdady M, Stewart RE, Watts P, Murphy PJ, Woodhouse JM. Bifocals and Down's syndrome: correction or treatment? Ophthalmic Physiol Opt. 2009;29(4):416-421. doi:10.1111/ j.1475-1313.2009.00646.x

117. de Weger C, Boonstra N, Goossens J. Bifocals reduce strabismus in children with Down syndrome: evidence from a randomized controlled trial. Acta Ophthalmol. 2020;98(1):89-97. doi:10.1111/ aos. 14186

118. Motley WW, Melson AT, Gray ME, Salisbury SR. Outcomes of strabismus surgery for esotropia in children with Down syndrome compared with matched controls. $J$ Pediatr Ophthalmol Strabismus. 2012;49(4):211-214. doi:10.3928/0191391320120207-04

119. Harrison A, Allen L, O'Connor A. Strabismus Surgery for Esotropia, Down Syndrome and Developmental Delay; Is an Altered Surgical Dose Required? A Literature Review. $\mathrm{Br}$ Ir Orthopt J. 2020;16(1):4-12. doi:10.22599/bioj.140

120. Ruttum MS, Kivlin JD, Hong P. Outcome of surgery for esotropia in children with down syndrome. American Orthoptic $J$. 2004;54:98-101. doi:10.3368/aoj.54.1.98

121. Perez CI, Zuazo F, Zanolli MT, Guerra JP, Acuña O, Iturriaga H. Esotropia surgery in children with Down syndrome. J AAPOS. 2013;17(5):477-479. doi:10.1016/j.jaapos.2013.06.007

122. Yahalom C, Mechoulam H, Cohen E, Anteby I. Strabismus surgery outcome among children and young adults with Down syndrome. $J$ AAPOS. 2010;14(2):117-119. doi:10.1016/j. jaapos.2010.01.009 


\section{Publish your work in this journal}

Eye and Brain is an international, peer-reviewed, open access journal focusing on clinical and experimental research in the field of neuroophthalmology. All aspects of patient care are addressed within the journal as well as basic research. Papers covering original research, basic science, clinical and epidemiological studies, reviews and

Submit your manuscript here: https://www.dovepress.com/eye-and-brain-journal evaluations, guidelines, expert opinion and commentary, case reports and extended reports are welcome. The manuscript management system is completely online and includes a very quick and fair peerreview system, which is all easy to use. Visit http://www.dovepress. com/testimonials.php to read real quotes from published authors. 